SIR,-The paper by Professor T. N. A. Jeffcoate and his colleagues (5 October, p. 19) is of great interest because of their confirmation of the association between puerperal thromboembolism and the use of oestrogens to inhibit lactation. There are differences between their findings and those of the original Cardiff Survey ${ }^{1}$ which are not likely to be due to differences in dosage or the oestrogen used.

In the Princess Mary Maternity Hospital lactation is usually suppressed with stilboestrol to a total dosage of $110 \mathrm{mg}$. In the years 1961-6 inclusive there were 14,018 deliveries, and among the 44 cases of significant thromboembolism requiring anticoagulants, in no fewer than 19 (43.2\%) of these cases the complication occurred during pregnancy. The relatively large number of venous thrombotic episodes in pregnancy, also noted in one of the Liverpool hospitals, appears to be a recent phenomenon. We are convinced that this high incidence represents a change in the pattern of the disease, rather than an improvement in diagnosis.

The incidence of puerperal thromboembolism is 1.6 per thousand births, which is very close to that found in Liverpool. We have formed a control group by selecting at random $1 \%$ of all case records during the period under study. There is every reason to believe that this group is representative of the population as a whole, and one can calculate that the incidence of thromboembolism in women who lactated was 0.5 per thousand compared with an incidence of 3.0 per thousand in women whose lactation was suppressed. Although our numbers are small certain tentative conclusions are possible.

As in the other reported studies, suppression of lactation does not seem to affect the incidence of thromboembolism in women under the age of 25 . Assisted delivery is associated with an increased risk of thromboembolism only in woman whose lactation was suppressed, and even among the latter group the increase was limited to patients delivered by caesarean section. Six of the $25(24 \%)$ patients were delivered abdominally as compared with a section rate of $9 \%$ in the control group. We agree with Professor Jeffcoate and colleagues that the factors of increasing age and parity when coupled with oestrogen suppression together increase the risk of thrombcembolism even when neither of them are effective separately.

A continuing paradox is the failure of the incidence of thrombosis in the puerperium to follow the change in breast feeding habits Fifteen years ago $10 \%$ of patients in this hospital had lactation suppressed; since then the incidence has increased steadily until by 1965 $75 \%$ were given oestrogens. These figures of the changing pattern of breast feeding agree more with the Scottish experience ${ }^{2}$ than with that quoted for Liverpool. However, during this period, as in Liverpool, there has been no increase in the incidence of puerperal thromboembolism (in contrast to the marked changes in the rate of thromboembolism in pregnancy). This suggests that the association between puerperal thromboembolism and the use of synthetic oestrogens to suppress lactation is not as clear-cut as the Cardiff workers suggested. Because of the low incidence of the disease and the many causal factors involved it is unlikely that any retrospective study from a single centre can give any precise measure of the risk of oestrogen administration. It is encouraging that large controlled prospective studies are already in progress. These ought also to indicate whether oestrogens are effective or indeed necessary to suppress lactation, since the evidence on this point is far from clear.-We are, etc.,

\section{G. Millar.}

E. G. ROBERTSON.

University of Newcastle upon Tyne,
Princess Mary Maternity Hospital,

Princess Mary Maternity Hosp
Newcastle upon Tyne 2.

REFERENCES

1 Daniel, D. G., Campbell, H., and Turnbull, Arneil. G. C., Scottish Health Service Study No. 6,1967 . Edinburgh.

\section{Rare Cause of Precordial Pain}

SiR,-A 57-year-old male was admitted urgently to the cardiac department of the Evangelismos Medical Center because of severe constricting retrosternal pain. This was of abrupt onset, although two to three weeks earlier he had experienced weakness, low-grade fever, mild dyspnoea, and cough.

On admission he was in a shocked state, blood pressure being $80 / 60 \mathrm{~mm}$. $\mathrm{Hg}$ and pulse rate $140 / \mathrm{min}$. There was dullness on percussion and greatly diminished breath sounds in the lower half of the left lung. W.B.C. were 22,000 / cu.mm., with $88 \%$ polymorphs and E.S.R. $88 \mathrm{~mm}$. in the first hour. Aspartate transaminase was 33 units, alanine transaminase 27 units, and serum amylase 120 Somogyi units \%. Chest $x$-ray showed stippled densities throughout the left lower lobe due to alveolar infiltration and small amount of fluid in the left pleural cavity. E.C.G. showed sinus tachycardia, with negative or biphasic T waves in I, II, AVL and $S T$ depression in $V_{2}-V_{6}$. The patient's condition continued to deteriorate rapidly, and he died 12 hours after his admission to the hospital.

Necropsy showed the middle portion of the oesophagus infiltrated by a soft tumour mass which had ruptured into the mediastinum and to a lesser extent into the main bronchus of the left lung. Microscopic examination of the tumour showed squamous cell carcinoma. The heart was of normal size without any occlusion of the coronary arteries.

The object of describing this case is to draw attention to this rare cause of praecordial pain that may simulate acute myocardial infarction. Contemporary investigators have accepted between 86 and 200 cases of spontaneous perforations of the oesophagus reported in the literature. ${ }^{1}$ On the other hand, spontaneous perforation of an oesophageal tumour without being previously subjected to radiotherapy seems to be extremely rare. Actually we were unable to find any case reported previously in the literature. Spontaneous perforation of the oesophagus, whether due to a tumour or not, may easily be confused with acute myocardial infarction. This is due to the location and character of the pain as well as the peripheral circulatory collapse that it may produce. ${ }^{1}$ The lack of specific E.C.G. changes in the oesophageal rupture helps to establish the correct diagnosis, but it is well known that in many cases of myocardial infarction these changes are found only on serial electrocardiograms. We are, etc.,

\section{Samaras.}

P. KAFKAS.

S. Chrysanthakopoulos.

Evangelismos Medical Center,

Athens, Greece.

\section{REFERENCE}

1 Tesler, M. A., and Eisenberg, M. M., Int. Abstr. Surg., 1963, 117, 1 .

\section{Unusual Cause of Yellow Skin}

SIR,-Perhaps you would allow us to draw the attention of your readers to an interesting and hitherto unreported side-effect of Salazopyrin (sulphasalazine).

A 73-year-old lady undergoing treatment for long-standing recurrent ulcerative co'itis developed a striking yellow pigmentation of the skin. Her serum was also bright yellow. The pigment was not bilirubin and her liver function tests were normal. In addition to local and systemic steroid therapy she was receiving sulphasalazine $4 \mathrm{~g}$./day. She was known to have impaired renal function, a blood urea at a previous admission being 98 mg. $/ 100 \mathrm{ml}$., and the present exacerbation of her ulcerative colitis had precipitated a uraemic state, peak blood urea $328 \mathrm{mg} . / 100$ $\mathrm{ml}$. Having noticed yellow staining of the tongue during administration of sulphasalazine, we guessed that abnormally high blood levels of the drug had been attained in our patient, due to inadequate renal excretion. Fearing the possibility of toxic side-effects, we carried out a peritoneal dialysis which rapidly returned the colour of her skin and serum to normal. Examination of the bright yellow serum, taken at the time of the pigmentation, by the method of Böttiger ${ }^{1}$ identified the colour as being due to sulphasalazine in a concentration of $30 \mathrm{mg} . / 100$ $\mathrm{ml}$. (a normal therapeutic blood level on a dose of $6 \mathrm{~g} . /$ day is $3-4 \mathrm{mg} . / 100 \mathrm{ml}$.). The patient recovered from her exacerbation of diarrhoea, and subsequent investigation revealed radiological evidence of chronic pyelonephritis. Her blood urea returned to $95 \mathrm{mg} . / 100 \mathrm{ml}$. and a 24-hour creatinine clearance was 20 $\mathrm{ml} . / \mathrm{min}$.

Despite the alarming yellow skin pigmentation and the high blood level of the drug inadvertently produced in this patient, we found no evidence of toxicity or other harmful effects. It is nevertheless worth making the point that sulphasalazine when given in normal dosage to patients with reduced renal function can cause yellow skin pigmentation which might be mistaken for jaundice.We are, etc.,

JOAN YELL.

G. D. SHIEL.

P. R. Uldall.

Dryburn Hospital,
Durham.

REFERENCB

L. E., Scand. 7. clin. Lab. Invest., 1958, 10. 108 .

\section{Folate Deficiency in Pregnancy}

SiR,-In your article on folic acid and combined iron and folic acid preparations in pregnancy (12 October, p. 102) the dosage of folic acid supplements for pregnant women at increased risk is discussed.

A trial concluded recently (in press) was limited to pregnant women in a population with exceptionally poor nutritional status. In addition, all the women were multiparous and the pregnancy immediately preceding the index pregnancy had been complicated by defective folate metabolism. It was found that $500 \mu \mathrm{g}$. folic acid daily was adequate to prevent folate deficiency in pregnancy and was as effective for this purpose as a dosage of $5 \mathrm{mg}$. daily. The population studied were known to be poorly motivated and were poor attenders at the antenatal clinics, but, as 